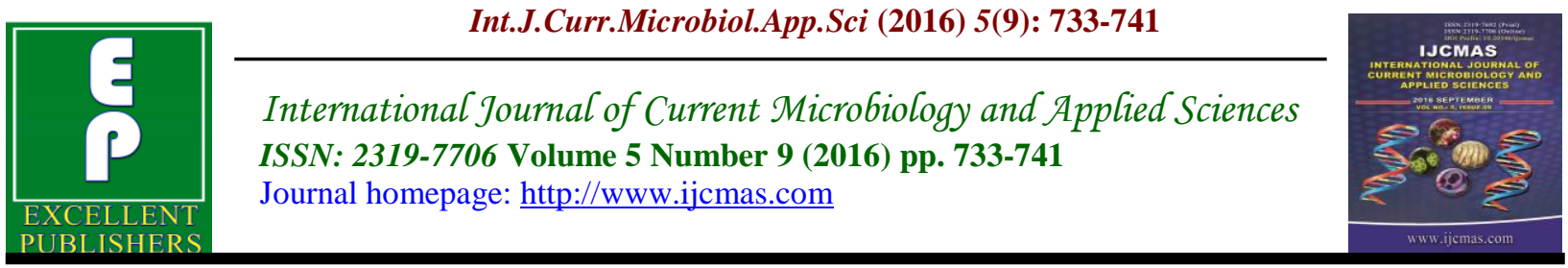

Original Research Article

http://dx.doi.org/10.20546/ijcmas.2016.509.084

\title{
Changing Strategies of Biochemical \& Physiological Features of Selected Plant Species on Effect of Air Pollution in Eastern Steel City, Durgapur, India
}

\author{
Shiboram Banerjee ${ }^{1 *}$, Debnath Palit ${ }^{2}$ and Arnab Banerjee ${ }^{3}$ \\ ${ }^{1}$ PG Department of Conservation Biology, Durgapur Govt. college, \\ Durgapur-713214, West Bengal, India \\ ${ }^{2}$ Department of Botany, Durgapur Govt. College, Durgapur-713214, West Bengal, India \\ ${ }^{3}$ U.T.D, Department of Environmental Science, Sarguja Viswavidyalaya, Ambikapur, \\ Chattisgarh-497001, India \\ *Corresponding author
}

A B S T R A C T

Keywords

Air pollution, ascorbic acid, $\mathrm{pH}$, total chlorophyll, relative water content, urban, Durgapur, India.

Article Info Accepted: 28 August 2016 Available Online: 10 September 2016
A study was conducted for the assessment of biochemical change on effect of air pollution of selective plant species around an industrial/ urban area Durgapur, India. Three biochemical parameters such as ascorbic acid, $\mathrm{pH}$ and total chlorophyll and one physiological parameter like relative water content (RWC) of eight different plant leaves were analyzed at two different regions of Durgapur Industrial belt. Ambient air quality (SOx, NOx and SPM) were also analyzed to evaluate the surrounding air pollution at each site. This study indicated that, plants can change their inert physio- biochemical mechanisms to withstand themselves in a more polluted environment, though it is not the property of all species of plants, only the tolerant one can do this. In the stressful environment the early diagnosis of plant species is the analysis of biochemical parameters rather than the detection of morphological anomaly which is late stage manifestation of plant life.

\section{Introduction}

The atmosphere is a complex, dynamic natural gaseous mixture that is essential to support life on planet earth. But pure air (i.e. air containing contaminants or pollutants within permissible limit) is rare now. The most important international problem is air pollution which damages the natural environment, as well as harm human and other living organisms. There has no physical or chemical method to diminish the more complex air pollution except growing green plants in and around urban and industrial areas (Agarwal, 1988; Santra, 1995; Thakre, 1995; Sannigrahi et al., 2003; Sivasamy and Srinivasan, 1996; Fukuoka, 1997; Ghosh and Majee, 2001). Well managed green belt development which trap and precipitate the pollutants very precisely will mandatory for every industrial zone in the world.

Durgapur is an industrial belt of West Bengal, India having big steel plants and many small scale industries continuously 
emitting air pollutants such as $\mathrm{SO}_{2}, \mathrm{NO}_{2}$, $\mathrm{CO}$, heavy metals and different suspended/ respirable particulate matter to the atmosphere. City's internal traffic load and 24 hours busy National Highway 2 which intersecting the city in the middle has exerted a profound influence on environment. Unplanned urbanization, increased level of industrialization and heavy traffic load pollute the air in daily and hourly basis.

This paper studied the effect of air pollution on some biochemical and physiological properties of selected plant species growing in severely polluted site of Durgapur steel city, Tamla which is the innermost site at the junction of Durgapur Steel Plant (DSP), Alloy Steel Plant (ASP) and Durgapur Project Limited (DPL). Another one is comparatively less polluted site, Jemua with no industrial activity.

This study provided a valuable assessment that, in response to various air pollutants plants differ markedly, some being highly tolerant and some are sensitive (Singh and Rao, 1983;Sannigrahi et al., 2003). The sensitivity and tolerance of plant species to pollutants can be defined by analyzing their biochemical and physiological parameters, such as, ascorbic acid content (Mukherjee and Chaudhuri, 1983), pH (Chaudhury and Rao,1977), total chlorophyll (Arnon, 1949) and relative water content (Sen and Bhandary, 1978). Singh and Rao (1983) have developed the Air Pollution Tolerance Index (APTI) which is based on the above parameters like ascorbic acid content, $\mathrm{pH}$, total chlorophyll and relative water content. Sensitive species are early indicator of pollution load and has lower APTI value; on the other hand tolerant one has higher APTI value and could be used for green belt development. Pollution status of a region becomes unambiguous by analyzing the
APTI values which is based on the above four biochemical parameters rather than by comparing the biochemical data separately of a single plant species.

\section{Materials and Methods}

\section{Sampling Site/ Samples collection}

Durgapur is an industrial hub of West Bengal, with an elevation of 65 meter from sea level. The undulating topography, lower water holding capacity and presence of various sizes of stone cheeps beneath the upper soil layer make the land unfertile for agriculture. In present investigation two different sites had chosen, one was Tamla (it lies within longitude $\mathrm{N} 23^{\circ} 32^{\prime} 01.15^{\prime \prime}$ and latitude $\mathrm{E} 87^{\circ} 18^{\prime} 21.29^{\prime /}$ ) which is severely polluted zone in respect to industrial activity along with heavy traffic load. The other site was Jemua (it lies within longitude $\mathrm{N}$ $23^{\circ} 32^{\prime} 57.15^{\prime \prime}$ and latitude E87 $20^{\prime} 40.9^{\prime \prime}$ ) which is a pristine forest zone of Durgapur and the pollution data revealed it has less air pollution. The eight selected matured plant leaf samples were collected during summer season of 2013 at the lower most portion of the canopy at a height of 5-15 ft. from the ground level. The same plant leaf samples were collected from both the sites along the roadside. After collection the samples were cleaned with distilled water and immediately refrigerated in laboratory for biochemical analysis.

\section{The Methods of Biochemical parameters}

The leaf samples were analyzed for biochemical estimation by the following methods like- ascorbic acid by Mukherjee and Chaudhuri, 1983; pH by Singh and Rao, 1983; total chlorophyll by Arnon, 1949 and relative water content by Sen and Bhandary, 1978. 


\section{Air Pollution Tolerance Index (APTI)}

Singh and Rao (1983) have developed an index, the Air Pollution Tolerance Index (APTI) which is based on the four above biochemical parameters of plant leaves. In this formula the product of ascorbic acid with sum of leaf extract $\mathrm{pH}$ and total chlorophyll is added with relative water content (RWC) and the whole is divided by 10. The following formula revealed the Air Pollution Tolerance Index (APTI) of plant leaves:

$\mathrm{APTI}=\frac{\mathrm{A}(\mathrm{T}+\mathrm{P})+\mathrm{R}}{10}$

Where, $\mathrm{A}=$ Ascorbic acid content $(\mathrm{mg} / \mathrm{gm}$. fresh weight)

$\mathrm{T}=$ Total Chlorophyll content $(\mathrm{mg} / \mathrm{gm}$. fresh weight)

$\mathrm{P}=\mathrm{pH}$ of the leaf extract

$\mathrm{R}=$ Relative water content of leaf $(\%)$

The range of APTI index is: 0 to $1=$ most sensitive

1 to $16=$ sensitive

17 to $29=$ intermediate

30 to $100=$ tolerant

\section{Statistical Analysis}

The correlation (between the said variables) and Hierarchical cluster analysis (between plant species and between said variables of both sites) were performed by Statistica for Windows, Version 5.1a, StatsoftInc, 1996 and SPSS Inc., 1999. By applying the statistical tools we have segregated the plant species depending on their biochemical and APTI values and also segregated biochemical parameters of both sites.

\section{Analysis of air pollutants}

Air pollution parameters like $\mathrm{SO}_{2}, \mathrm{NO}_{2}$ and SPM (Suspended Particulate Matter) were measured by a Handy Air Sampler (Envirotech Model APM 821).

\section{Results and Discussion}

Table 1 shows the comparative biochemical features of eight selected plant species at site Jemua which is without industrial activity and site Tamla which is severely polluted with high industrial activity and heavy traffic load. In Jemua the recorded ascorbic acid content was highest in Anthocephalus kadamba (74.59 $\mathrm{mg} \mathrm{g}^{-1}$ fresh weight) followed by Alstonias cholaris (63.06), Pongamia pinnata(31.09), Dalbergia sissoo (15.91), Shorearo busta(8.38), Mangifera indica (5.05), Ficus religiosa (3.98) and Ficus benghalensis (1.11). Similarly the ascorbic acid content in severely polluted site Tamla recorded as followsAnthocephalus kadamba (194.96 $\mathrm{mg} \mathrm{g}^{-1}$ fresh weight) and Alstonias cholaris (188.85 $\mathrm{mg} \mathrm{g}^{-1}$ fresh weight) has highest value, the highest values was also noted for these two plants in Jemua. Other plants of Tamla showed the higher values of this acid content such as, Shorearo busta (89.42), Ficus religiosa (82.80), Pongamia pinnata (65.68), Mangifera indica (45.24), Dalbergia sissoo (42.70) and Ficus benghalensis (15.03). The important finding was the ascorbic acid content increased comparatively of all plant species in polluted site Tamla as the low molecular mass ascorbic acid act as an antioxidant which is generated under oxidative stress. In plant body oxidative stress has been induced by several environmental factors including oxygen shortage, pollution, pathogen attack, pesticide application etc (Blokhina et al. 2003). This result showed that the increased ascorbic acid content of the same plant 
species in Tamla reflect that they have adapted themselves in this polluted stressful environment by increasing their inert biochemical features.

$\mathrm{pH}$ is one of the factor which also indicate impacts of air pollution on plant body. In Jemua the highest value was observed in Ficus religiosa (7.62) and the other species exhibited acidic nature of $\mathrm{pH}$ ranged between 4.03 to 5.75. In Tamla highest $\mathrm{pH}$ value was noted in Ficus benghalensis (6.85) and the remaining showed acidic $\mathrm{pH}$ ranged between 3.99 to 6.68 . Air pollutants mostly SOx, NOx and COx diffuse into the plant leaves and reacting with stomatal and cellular water and lowering the $\mathrm{pH}$. The plants having higher $\mathrm{pH}$ can overcome the more stressful condition of air (Agarwal, 1986). In comparison the higher $\mathrm{pH}$ values of plants in Tamla showed that, they were continuously battling against environmental poisonous gases by maintaining their internal ionic balance which is also an adaptation.

Chlorophyll is a photosynthetic molecule present inside the grana of chloroplast organelle and its main function is to convert the sun light energy to energy molecule glucose which mobile the earth biota. This chlorophyll becomes faint or low in impacts of air pollutants but the tolerant species has higher value (Joshi et al., 1993) and keep their net primary production same as compared to non-polluted sites.

Air pollution tolerance of plants depends on the higher chlorophyll contents. The plants exposed to high air pollution stress has a considerable loss of chlorophyll molecule as the SOx, NOx and particulate matter partially destroy the green molecule (Tripathy and Gautam, 2007). The highest total chlorophyll content was recorded in Alstonia scholaris (343 $\mathrm{mg} \mathrm{g}^{-1}$ fresh weight) and lowest in Dalbergia sissoo $\left(1.83 \mathrm{mg} \mathrm{g}^{-1}\right.$ fresh weight) in site Jemua. On the other hand Mangifera indica $\left(2.72 \mathrm{mg} \mathrm{g}^{-1}\right.$ fresh weight) has the highest value and Pongamia pinnata (1.33 $\mathrm{mg} \mathrm{g}^{-1}$ fresh weight) has the lowest value in site Tamla.

One of the physiological parameter to calculate the APTI values of plant species is Relative Water Content (RWC) which helps to regulate physiological water balance under stress condition (Dedio, 1975). In Jemua the highest value was recorded in Ficus religiosa $(93.68 \%)$ and the lowest value in Mangifera indica (3.49\%), whereas the plant species in site Tamla the relative water content was highest in Ficus religiosa $(93.68 \%)$ and lowest in Dalbergia sissoo (70.00\%). Though all the plant species not having higher RWC in Tamla as compared to site Jemua, in spite of that the plants continuously struggling for their existence in polluted site from different aspects.

Correlations between biochemical (total 4 factor) and APTI for non-polluted site Jemua and severely polluted site Tamla are presented in table 2 and table 3 respectively. Significant positive correlations between APTI and ascorbic acid were noted for Jemua $(\mathrm{r}=0.988)$ and Tamla $(\mathrm{r}=0.980)$ at 1 $\%$ level of significance.

On the other hand, APTI is positively correlated with total chlorophyll for Jemua but insignificant at $1 \%$ level of significance. This positive correlation of ascorbic acid with APTI in both sites reflects that, this factor is mainly responsible for higher tolerance of plant species against air pollution.

Hierarchical cluster analysis of the plants depending on the biochemical and APTI values of study site Jemua (Fig. 1) and Tamla (Fig. 2) were interesting to compare. In Jemua, five distinct clusters were observed. Ficus religiosa, Shorearobusta 
and Dalbergiasissoo form clusters which were much nearer to form another cluster with Ficus benghalensis. Pongamia pinnata form a cluster with previous two and these three clusters were much nearer with each other. Alstonia scholaris and Anthocephalus kadamba form the fourth cluster and was furthest from the earlier three clusters. Lastly Mangifera indica has kept itself far farthest from the earlier clusters.

Here mainly APTI values are influential for these clustering patterns. Alstonia scholaris and Anthocephalus kadamba have high APTI values, so they form a cluster, while Mangifera indica has lowest APTI and was farthest.

In Tamla (Fig. 2), four distinct clusters were observed. Alstonia scholaris and Anthocephalus kadamba were much nearer as it has been observed in Fig 1.These two plants were furthest from the clusters of other six plant species. Dalber giasisso, Mangifera indica and Pongamia pinnata formed one cluster and Ficus benghalensis, another one and they were much closer suggesting their similarity so far as the APTI values were concerned. The last and fourth cluster was formed by Ficus religiosa and Shorearo busta which have moderate APTI values.

In Fig. 3 reflect the same dendrogram of both sites were made by Air Pollution Tolerance Index (APTI) and biochemical parameters based on different selective plant species. This Fig. 3 showed that there are two distinct clusters. Ascorbic acid (AA) and APTI form a cluster because they are more nearer and their value influences each other positively.

A study related to the measurement of APTI of climber plant species revealed that there is a high positive correlation between APTI and ascorbic acid content (Pandeya et al. 2015). On the other hand $\mathrm{pH}$ and total chlorophyll (TCh) form a cluster which form another cluster with relative water content (RWC) and was farthest from the first cluster. The second cluster showed a closest similarity with ascorbic acid of the first suggesting that the four variables i.e. AA, $\mathrm{pH}$, TCh and RWC are the raw material for constructing an individual plant APTI.

There are two different dendrogram of the same plant species in two different sites depending on biochemical and APTI values. These two figures (Fig. 1 and Fig. 2) state that the different arrangements of plants in dendrogram reflect the changing environmental conditions which influenced on the plant species of both sites.

The air pollution data revealed that, in Jemua the SOx, NOx and SPM values were within normal limit i e. $10.02 \mu \mathrm{g} / \mathrm{m}^{3}, 17.13$ $\mu \mathrm{g} / \mathrm{m}^{3}$ and $48.01 \mu \mathrm{g} / \mathrm{m}^{3}$ respectively. On the other hand in Tamla the SOx, NOx and SPM results were $60.12 \mu \mathrm{g} / \mathrm{m}^{3}, 118.62 \mu \mathrm{g} / \mathrm{m}^{3}$ and $532.10 \mu \mathrm{g} / \mathrm{m}^{3}$ respectively. The changing biochemical features of the same plant species on effect of air pollution in both sites is a characteristics features of tolerant ones.

In Jemua the highest APTI value was recorded in Anthocephalus kadamba (62.39) and lowest in Mangifera indica(3.60), on the other hand in Tamla the highest value occupied by Alstonia scholaris (136.40) and lowest value by Ficus benghalensis (21.34).

There is a range of APTI index which indicates that, plants having APTI value 0-1 is most sensitive to air pollution; those having 1-16 is sensitive; the APTI value 1729 is intermittently tolerant and the plants having APTI values 30-100 considered as tolerant to air pollution (Mashita and Pise, 2001). 
Table.1 Ascorbic acid, pH, Total Chlorophyll and Relative Water Content of different plant species at Jemua (a relatively non polluted site in Durgapur)

\begin{tabular}{|c|c|c|c|c|c|c|c|c|c|c|}
\hline \multirow{2}{*}{$\begin{array}{l}\text { Name of the } \\
\text { Plant Species }\end{array}$} & \multicolumn{2}{|c|}{ Ascorbic acid } & \multicolumn{2}{|c|}{$\mathrm{pH}$} & \multicolumn{2}{|c|}{ Chlorophyll } & \multicolumn{2}{|c|}{ RWC } & \multicolumn{2}{|c|}{ APTI } \\
\hline & Jemua & Tamla & Jemua & Tamla & Jemua & Tamla & Jemua & Tamla & Jemua & Tamla \\
\hline Alstoniascholaris (L.)R.Br. & 63.06 & 188.85 & 5.06 & 5.21 & 3.43 & 1.58 & 57.44 & 81.76 & 59.28 & 136.40 \\
\hline Anthocephaluskadamba (Roxb.)Miq. & 74.59 & 194.96 & 4.03 & 3.99 & 3.09 & 1.80 & 92.91 & 86.96 & 62.39 & 121.57 \\
\hline DalbergiasissooRoxb. & 15.91 & 42.70 & 5.75 & 5.77 & 1.83 & 2.31 & 87.31 & 70.00 & 20.79 & 41.50 \\
\hline Ficus benghalensis L. & 1.11 & 15.03 & 5.48 & 6.85 & 1.97 & 2.13 & 68.07 & 78.49 & 7.63 & 21.34 \\
\hline Ficus religiosa $\mathrm{L}$. & 3.98 & 82.80 & 7.62 & 6.68 & 2.95 & 2.05 & 93.68 & 92.88 & 13.57 & 81.57 \\
\hline Mangifera indica $\mathrm{L}$. & 5.05 & 45.24 & 4.33 & 4.33 & 2.11 & 2.72 & 3.49 & 86.91 & 3.60 & 40.58 \\
\hline Pongamiapinnata (L.) Pierre & 31.09 & 65.68 & 5.51 & 5.75 & 2.27 & 1.33 & 79.13 & 83.10 & 32.10 & 54.81 \\
\hline ShorearobustaGaertn. & 8.38 & 89.42 & 4.33 & 5.23 & 2.93 & 2.15 & 87.56 & 78.56 & 14.83 & 73.84 \\
\hline
\end{tabular}

\section{Table. 2 \& 3}

\begin{tabular}{|c|c|c|c|c|c|c|c|c|c|}
\hline $\begin{array}{l}\text { Table } \\
\text { (forJen } \\
\text { total ch }\end{array}$ & $\begin{array}{l}\text { ** Correl } \\
\text { Paramete } \\
\text { phyll (TCh }\end{array}$ & $\begin{array}{l}\text { ation is } \\
\text { s are ab } \\
\text { and rel } \\
\end{array}$ & $\begin{array}{l}\text { nificant } \\
\text { viated as } \\
\text { water c }\end{array}$ & $\begin{array}{l}\text { at the } 0.01 \text { level (2-tailed). } \\
\text { follows: ascorbic acid (AA), } \\
\text { ontent (RWC). }\end{array}$ & $\begin{array}{l}\text { Table } \\
\text { Param } \\
\text { (TCh) }\end{array}$ & $\begin{array}{l}\text { * Correlati } \\
\text { are abbre } \\
\text { relative wa }\end{array}$ & $\begin{array}{l}\text { on is sign } \\
\text { iated as } \\
\text { er conten }\end{array}$ & $\begin{array}{l}\text { ant at the } \\
\text { ows: asco } \\
\text { WC). }\end{array}$ & $\begin{array}{l}0.01 \text { level (2-tailed). (forTamla). } \\
\text { rbic acid (AA), total chlorophyll }\end{array}$ \\
\hline & & & & & & & & & \\
\hline pH & -0.403 & pH & & & pH & -0.556 & pH & & \\
\hline TCh & 0.611 & -0.082 & TCh & & TCh & -0.508 & -0.1 & TCh & \\
\hline RWC & 0.189 & 0.356 & 0.259 & RWC & RWC & 0.31 & -0.144 & -0.108 & RWC \\
\hline APTI & $0.988^{* *}$ & -0.3 & 0.655 & 0.294 & APTI & $0.980^{* *}$ & -0.443 & -0.514 & 0.357 \\
\hline
\end{tabular}


Fig.1 Hierarchical cluster analysis of the plants under study site Jemua depending on the biochemical and APTI values

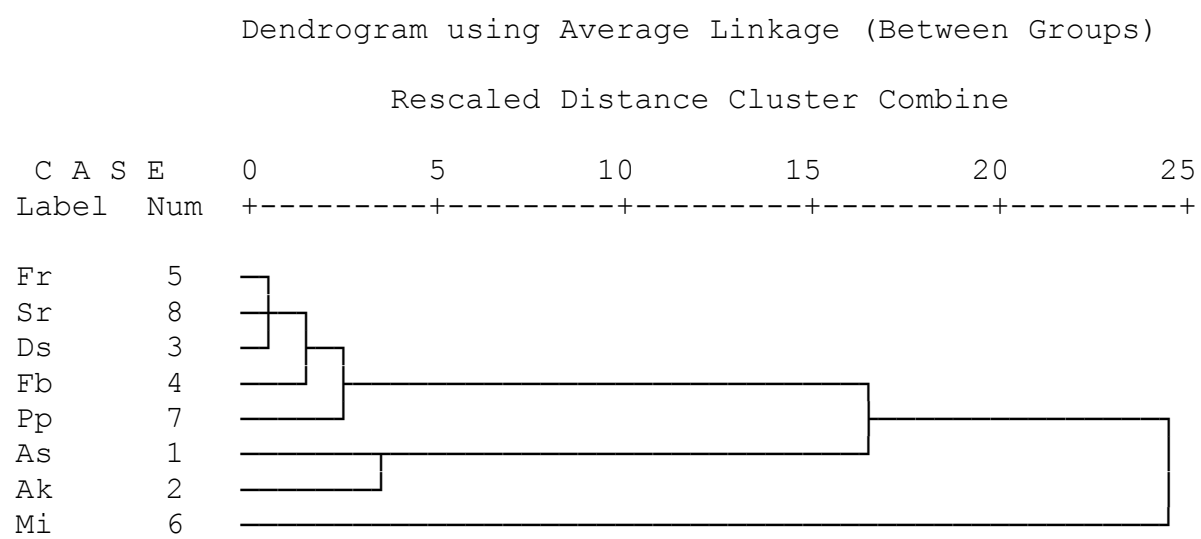

Plants code 1=Alstonia scholars (As), 2=Anthocephaluskadamba(Ak), 3=Dalbergiasissoo (Ds), 4=Ficus benghalensis $(\mathrm{Fb}), 5=$ Ficus religiosa $(\mathrm{Fr}), 6=$ Mangifera indica $(\mathrm{Mi}), 7=$ Pongamiapinnata $(\mathrm{Pp}), 8=$ Shorearobusta (Sr).

Fig.2 Hierarchical cluster analysis of the plants under study site Tamla depending on the biochemical and APTI values

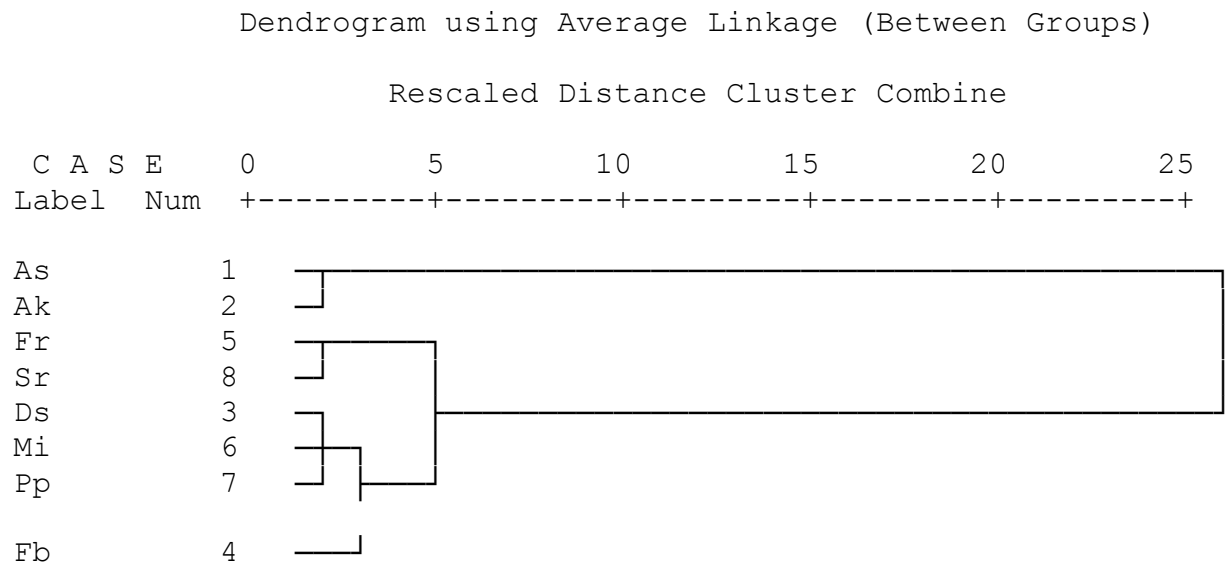

Plants code 1=Alstonia scholars (As), 2=Anthocephaluskadamba(Ak), 3=Dalbergiasissoo (Ds), 4=Ficus benghalensis $(\mathrm{Fb}), 5=$ Ficus religiosa $(\mathrm{Fr}), 6=$ Mangifera indica $(\mathrm{Mi}), 7=$ Pongamiapinnata $(\mathrm{Pp}), 8=$ Shorearobusta $(\mathrm{Sr})$.

Fig.3 Hierarchical cluster analysis of biochemical and APTI values of site Jemua and Tamla depending on the different selective plant species.

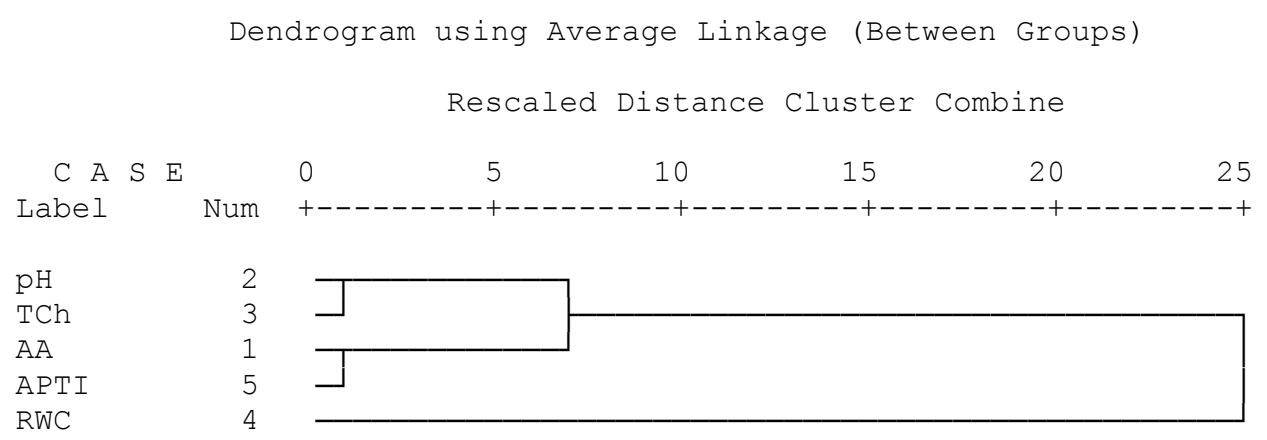


According to this scale in JemuaMangifera indica (3.60), Ficus benghalensis (7.63), Ficus religiosa (13.57) and Shorearo busta (14.83) were sensitive; Dalbergia sissoo (20.79) was intermittently tolerant and remaining three i.e. Pongamia pinnata (32.10), Alstonia scholaris (59.28) and Anthocephalus kadamba (62.39) were highly tolerant to air pollution. In Tamla Ficus benghalensis (21.34) was intermittently tolerant and remaining seven plant species were tolerant to air pollution. This study reflects that, plants follow strategies to change their biochemical property in face of air pollution to survive their successor.

In conclusion, the APTI values revealed that the plants which were sensitive or intermittently tolerant in one place might become tolerant in other place in eye of air pollution. But in this study Alstonia scholaris and Anthocephalus kadamba have positioned themselves as a tolerant species against air pollution in both the sites. So the pollution status of any region could be detected through analyzing the biochemical characteristics of plant species as fast as possible rather than morphological anomaly.

\section{Acknowledgement}

The authors are thankful to the authorities of Durgapur Steel Administration for giving permission to sample plant leaves in and around industrial region. Authors are also thankful to the Professors of Conservation Biology to carry forward the research work.

\section{References}

Agarwal, S.K. 1986. A new distributional function of foliar phenol concentration in the evaluation of plants for their air pollution tolerance index. Acta Ecol., 8(2): 29-36.

Agarwal, A.L. 1988. Air pollution control studies and impact assessment of stack and fugitive emissions from CCI Akaltara cement factory. Report (NEERI, Nagpur, India, 1988).

Arnon, D.I. 1949. Copper Enxymes in Isolated Chloroplasts Polyphenol Oxidase in Beta Vulgaris. Plant Physiol., 24(1): 1-15.

Beckett, K.P., Freer-Smith, P.H., and Taylor, G. 1998. Urban woodlands: their role in reducing the effects of particulate pollution. Environ. Pollut., 99: 347-360.

Bell, J.N.B., and Mudd, C.H. 1976. Sulfur dioxide resistance in plants: a case study of Loliumperenne (L.). In: Mansfield, T.A. (Ed.), Effects of Air Pollution on Plants. Cambridge University Press, 87103.

Blokhina, O., Virolinen, E., and Fagerstedt, K.V. 2003. Antioxidants, Oxidative Damage and Oxygen Deprivation Stress: a Review. Annals of Bot., 91: 179-194.

Chaudhary, C.S., and Rao, D.N. 1977. A study of some factors in plants controlling their susceptibility to $\mathrm{SO} 2$ pollution. Proceedings of Indian Nat. Sci. Acad., 43: 236-241.

CPCB Guidelines for developing greenbelts, CPCB Publication Programme Objective Series. PROBES/75. 1999 - 2000.

Constantinidou, H.A., and Kozlowski, T.T. 1979. Effect of sulpher dioxide and ozone on Ulmusa mericana seedling II; carbohydrate, protein and lipids. Can. J. Bot., 57: 176-184.

Davison, A.W., and Barners, G.D. 1986. Effects of winter stress on pollutant responses In; How are the effects of air pollutants on agricultural crops influenced by the interaction with other limiting factor? CEC, Brussels. 16-32.

Dedio, W. 1975. Water Relations in wheat leaves as Screening Test for Drought Resistance. Can. J. Plant Sci., 55: 369378.

Fukuoka, Y. 1997. Biometeorological studies on urban climate. Int. J. Biometeorol., 40(1): 54-57.

Ghose, M.K., and Majee, S.R. 2001. Air pollution caused by opencast mining and 
its abatement measures in India. $J$. Environ. Manage., 63(2): 193-202.

Gupta, S., Chattopadhyay, S., Saha, R.N., and Roy, S. 2009. Ambient air quality 106 Int. Res. J. Plant Sci. status of Burdwan town, West Bengal. Pollu. Res., 28(4): 643647.

Joshi, O.P., Pawar, K., and Wagela, D.K. 1993. Air quality monitoring of Indore city with special reference to $\mathrm{SO} 2$ and tree barks pH. J. Environ. Biol., 14(2): 157-162.

Mukherjee, S.P., and Chaudhuri, M.A. 1983. Implications of water stress-induced changes in the levels of endogenous ascorbic acid and hydrogen peroxide in Vigna seedlings. Physiologia Plantarum, 58: 166-170.

Pandeya, A.K., Pandeya, M., Mishra, A., Tiwary, S.M., and Tripathi, B.D. 2015. Air Pollution Tolerance Index And Anticipated Performance Index of some plant species for development of urban forest. Urban Forestry \& Urban Greening 14: 866-871.

Pandeya, A.K., Pandeya, M., and Tripathi, B.D. 2015. Air Pollution Tolerance Index of climber plant species to develop Vertical Greenery Systems in a polluted tropical city. Landscape and Urban Planning, 144: 119- 127.

Santra, S.C. 1995. Greenbelts for pollution abatements. In: Advances in Environmental Science and Technology (Trivedy RK, Ed.). 1: 283- 295 (Ashish Publishing House, New Delhi, India).
Sen, D.N., and Bhandari, M.C. 1978. Ecological and water relation to two Citrullus spp. In: Althawadi, A.M. (Ed.). Indian Arid Zone. Environ. Physiol. Ecol. Plants, pp. 203-228.

Shannigrahi, A.S., Sharma, R.C., and Fukushima, T. 2003. Air pollution control by optimal greenbelt development for Victoria Memorial Monument, Kolkata (India). Int. J. Environ. Studies, 60(3): 241-249.

Singh, S.K., and Rao, D.N. 1983. Evaluation of the plants for their tolerance to air pollution Proc. Symp on Air Pollution control held at IIT, Delhi 218-224.

Singh, S.K., Rao, D.N., Agrawal, M., Pandey, J., and Narayan, D. 1991. Air Pollution Tolerance index of plants. J. Environ. Manage., 32: 45-55.

Sivasamy, N. and Srinivasan, V. 1996. Environmental pollution and its control by trees. (Indian Agriculture Research Institute IARI, Pusa, New Delhi, India).

Thakre, R. 1995. Green belt for pollution abatement. In: Encyclopedia of Environ. Pollu. Control, I: 337-349 (Enviro Media, Karad, Maharastra, India).

Tripathi, A.K., and Gautam, M. 2007. Biochemical parameters of plant as indicators of air pollution. 28(1): 127132.

Yan-Ju, L., and Hui, D. 2008. Variation in air pollution tolerance index of plant near a steel factory; implications for landscapeplant species selection for industrial areas. Environ. Develop., 1(4): 24-30.

\section{How to cite this article:}

Shiboram Banerjee, Debnath Palit and Arnab Banerjee. 2016. Changing Strategies of Biochemical \& Physiological Features of Selected Plant Species on Effect of Air Pollution in Eastern Steel City, Durgapur, India. Int.J.Curr.Microbiol.App.Sci. 5(9): 733-741. doi: http://dx.doi.org/10.20546/ijcmas.2016.509.084 